\title{
The Use of Intravenous and Aerosolized Polymyxins for the Treatment of Infections in Critically III Patients: A Review of the Recent Literature
}

\author{
Matthew E. Falagas, MD; Sofia K. Kasiakou, MD; Sotirios Tsiodras, MD; and Argyris Michalopoulos, MD
}

\begin{abstract}
Intravenous and aerosolized polymyxins are being used increasingly, especially in the critical care setting, for treating patients with infections due to multidrug-resistant Gram-negative bacteria, mainly Acinetobacter baumannii and Pseudomonas aeruginosa. Recent literature suggests that intravenous colistin and polymyxin B have acceptable effectiveness for the treatment of patients with bacteremia, as well as infections of various systems and organs, including pneumonia, bacteremia, skin and soft tissue, and urinary tract infections. Although data from recent studies have suggested that the toxicity of intravenous polymyxins is probably less than reported in the older literature, caution should be taken to monitor the renal function of patients who receive these antibiotics.
\end{abstract}

Keywords: Acinetobacter; Colistin; Inhalation; Intensive care unit; Klebsiella; Multidrug-resistant Gram-negative bacteria; Nebulization; Pneumonia;

Polymyxin B; Pseudomonas; Ventilator-associated

卫 in combination with the emergence of Gram-negative bacteria that produce extended spectrum $\beta$-lactamases and metallo- $\beta$-lactamases, represent major health threats that affect patient outcomes, particularly in the intensive care unit. Strains of Acinetobacter baumannii, Pseudomonas aeruginosa and Klebsiella pneumoniae that exhibit resistance to almost all available antibiotics, except polymyxins, have emerged as common causes of hospital acquired infections in critically ill patients. ${ }^{1-3}$ Polymyxins have been recently considered as last therapeutic options for the treatment of patients with these types of infections. In addition, the administration of polymyxins intrathecally or intraventricularly has been evaluated recently as a potential alternative intervention for the treatment of multidrug-resistant Gram-negative central nervous system infections. Although the level of evidence to support the use of polymyxins by these modes of administration is low, the reported data are promising. ${ }^{4-6}$

History, Mechanism of Action and Spectrum of Activity Polymyxins are a group of polypeptide cationic antibiotics. ${ }^{7}$ Major components of this class of antimicrobial agents that have been used in clinical practice represent colistin (polymyxin E) and polymyxin B. Colistin and polymyxin B were discovered from different species of Bacillus polymyxa in the 1940s and were extensively used parenterally for approximately two decades, after which they were gradually withdrawn from clinical practice owing to reports of toxicity. ${ }^{8-12}$ Specifically, several studies that assessed the safety of parenteral polymyxins reported frequent development of renal and neurological adverse effects. ${ }^{13,14}$ In addition, numerous case reports published in the $1960 \mathrm{~s}$ and 1970s associated the administration of polymyxins with the development of acute renal failure. ${ }^{15-17}$

Polymyxins consist of a cyclic decapeptide molecule, which is positively charged and linked to a fatty acid chain that has been found to be either 6-methyl-octanic acid or 6-methyl-eptanoic acid. The main difference between the molecules of polymyxin $\mathrm{B}$ and colistin is in the amino acid components. ${ }^{7}$ Colistin consists of D-leucine, L-threonine and L- $\alpha \gamma$-diaminobutyric acid, while polymyxin B contains D-phenylalanine instead of D-leucine. ${ }^{7}$ The cationic molecules of polymyxin B and colistin compete and displace $\mathrm{Ca}^{2+}$ and $\mathrm{Mg}^{2+}$ ions which normally stabilize the lipopolysaccharide molecule of the outer membrane of Gram-negative bacteria. This 
outer membrane of Gram-negative bacteria. This displacement causes local disturbance of the cell membrane, increased cell permeability, leakage of the cell content, cell lysis and death. ${ }^{18,19}$ In addition, a remarkable property of polymyxins is the ability to neutralize lipopolysaccharide molecules of Gram-negative bacteria, thus inducing anti-endotoxin activities. ${ }^{20}$ In patients with sepsis, continuous hemodialysis therapy with polymyxin-B immobilized fiber has been correlated with improvement of the survival rates. ${ }^{21}$ Their spectrum of activity includes Gram-negative aerobic bacilli only, including Acinetobacter baumannii, Pseudomonas aeruginosa, Klebsiella species, Enterobacter species, Salmonella species, Shigella species and Escherichia coli. Stenotrophomonas maltophilia strains are usually susceptible to polymyxins. ${ }^{22,23}$ On the other hand Proteus species, Serattia species, Burkholderia species, Providencia species and Edwardsiella spp. are resistant to polymyxins. ${ }^{22}$

\section{Dosage and Pharmacokinetic/Pharmacodynamic Properties}

Two forms of colistin are commercially available for clinical use: 1) colistin sulfate that is usually used topically or orally for selective bowel decontamination, and 2) colistimethate sodium that is used parenterally. Polymyxin B is commercially available as polymyxin B sulfate.

The dosage of intravenous colistin base recommended by the manufacturer in the United States is $2.5-5 \mathrm{mg} / \mathrm{kg}$ per day divided into 2 to 4 equal doses. It should be noted that the formulation of colistin manufactured in the U.S. by Parkedale Pharmaceuticals Inc. (Rochester, MI) and distributed by Monarch Pharmaceuticals Inc. (Bristol, TN) contains $150 \mathrm{mg}$ colistin base. ${ }^{24}$ Dosage adjustments are recommended for patients with mild to moderate renal dysfunction. Specifically, when the serum creatinine level is $1.3-1.5 \mathrm{mg} / \mathrm{dl}$, $1.6-2.5 \mathrm{mg} / \mathrm{dl}$ or $\geq 2.6 \mathrm{mg} / \mathrm{dl}$, the recommended dosage of intravenous colistin for serious infections is 2 million IU every 12 hours, 24 hours or 36 hours, respectively. In the United Kingdom, a dosing regimen of $4-6 \mathrm{mg} / \mathrm{kg}$ $(50,000-75,000 \mathrm{IU} / \mathrm{kg})$ of colistimethate sodium per day in 3 divided doses is recommended for adults and children with normal renal function and body weight $\leq 60 \mathrm{~kg}$, and $240-480$ mg (3-6 million IU) per day in 3 divided doses for those with body weight $>60 \mathrm{~kg}$. This formulation, which is manufactured by Alpharma A/S (Copenhagen, Denmark) and distributed by Forest Laboratories (Kent, United Kingdom) contains $80 \mathrm{mg}$ of colistimethate sodium ( $1 \mathrm{mg}$ of colistimethate sodium is equal to $12,500 \mathrm{IU}){ }^{25}$ To avoid confusion regarding dosing of colistin, it is preferable to use a dosing system based on International Units (IU). Pure colistin base has a potency of $30,000 \mathrm{IU} / \mathrm{mg}$. The dosage of intravenous polymyxin B recommended by the manufacturer is $1.5-2.5 \mathrm{mg} / \mathrm{kg} / \mathrm{day}$ (15,000-25,000 IU/kg/day), divided into 2 equal doses for adults and children older than 2 years with normal renal function. One milligram of polymyxin B is equal to 10,000 IU. ${ }^{26}$ Recommendations for dosage adjustment of polymyxin $\mathrm{B}$ in the presence of renal impairment have not been well established. For both regimens, there are no dosage adjustments for patients with liver failure. It should be noted that neurotoxicity, including neuromuscular blockade and apnea, has been observed with high doses of colistimethate sodium administered intravenously, and it more commonly presents in patients with renal dysfunction when the dosage is not adjusted.

The dosage of aerosolized colistimethate sodium recommended in the United Kingdom is $40 \mathrm{mg}$ (500,000 IU) every 12 hours for patients with body weight $\leq 40 \mathrm{~kg}$, and 80 mg ( 1 million IU) every 12 hours for patients with a body weight $>40 \mathrm{~kg}$. For recurrent pulmonary infections, the dosage can be increased to $160 \mathrm{mg}$ ( 2 million IU) every 8 hours. $^{27}$

The precise pharmacokinetic-pharmacodynamic properties of polymyxin B and colistimethate sodium have not been completely clarified, and most of the available literature was published approximately three decades ago. However, both polymyxins are poorly absorbed by the gastrointestinal tract following oral administration and are eliminated by the renal route. No hepatic excretion of polymyxin $B$ and colistimethate sodium has been reported in humans. ${ }^{28}$ Both polymyxins have rapid concentration dependent bactericidal activity against Gram-negative pathogens ${ }^{29}$ and exhibit considerable post-antibiotic effects at high concentrations. ${ }^{28,30}$

\section{Intravenous Polymyxins in Critically III Patients}

No well-designed, randomized controlled trials (phase II or III trials) have been conducted to comprehensively evaluate the effectiveness and safety of polymyxins for the treatment of Gram-negative bacterial infections and to elucidate their clinical indications. However, the need for their use in patients with infections caused by polymyxin-only susceptible microorganisms or with infections where the available antimicrobial therapeutic options have failed, has led to the accumulation of valuable experience regarding their usefulness.

Table 1 (pages 140-142) summarizes recently published studies that assessed the effectiveness and safety of parenteral polymyxin B and colistimethate sodium for the treatment of critically ill patients with multidrug-resistant Gram-negative bacterial infections. Both medications have been used parenterally in cases of pneumonia, bacteremia, urinary tract infections, surgical site infections, abdominal infections, skin and central nervous system infections. Most recently published studies included severely ill patients with Acute Physiology and Chronic Health Evaluation II (APACHE II) scores ranging from 13 to 26 who suffered from infections caused by multidrug-resistant or polymyxin-only-susceptible Gram-negative bacteria. The observed frequency of clinical cure among patients in these studies was promising. However, a major limitation observed in most of these studies is that combinations of colistimethate sodium and polymyxin B with other antimicrobial agents were used due to the severity of the infections in the intensive care 


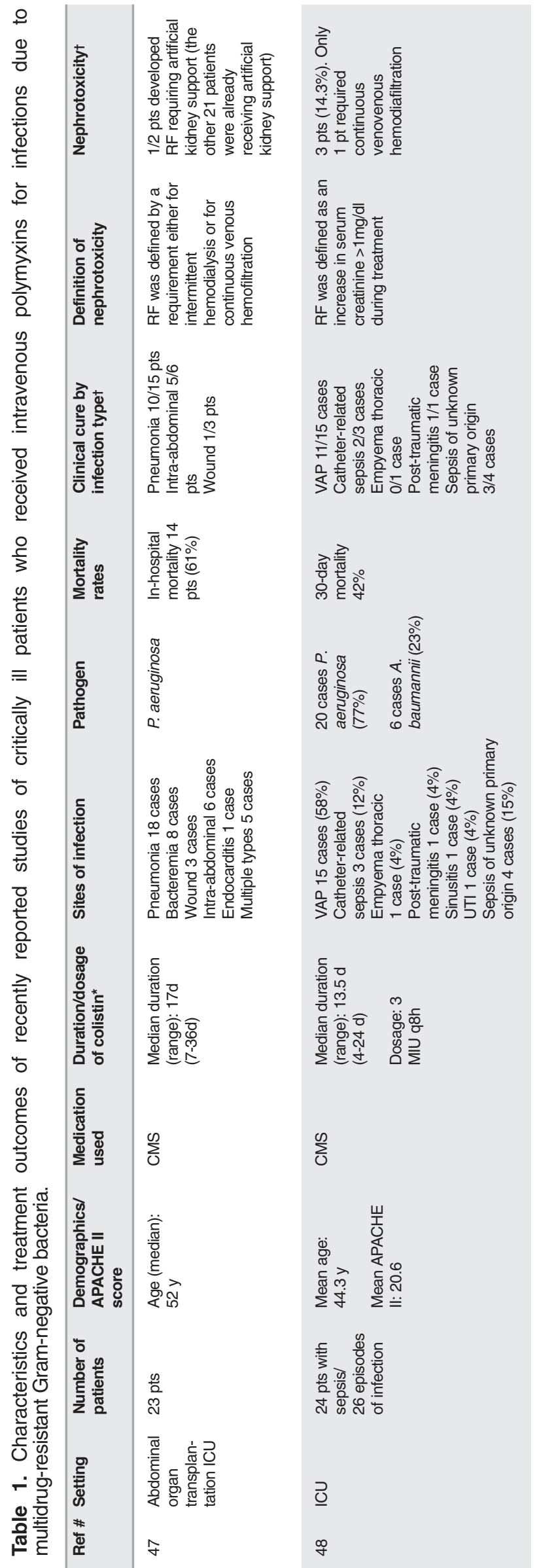

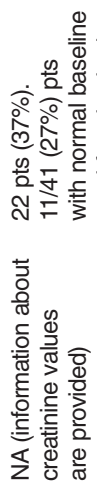

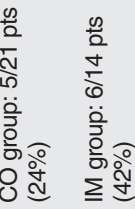

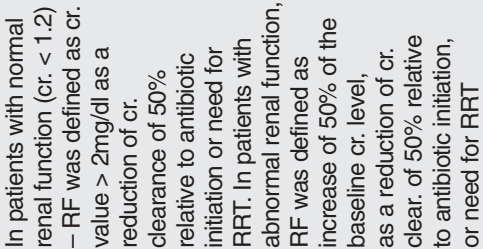

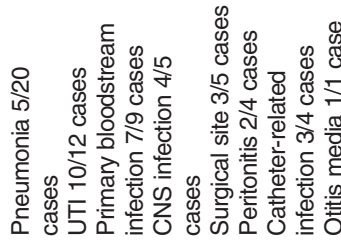

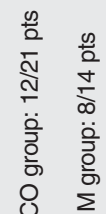

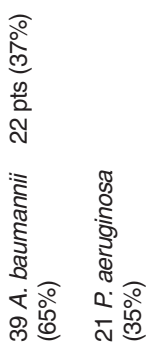

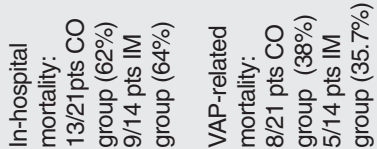
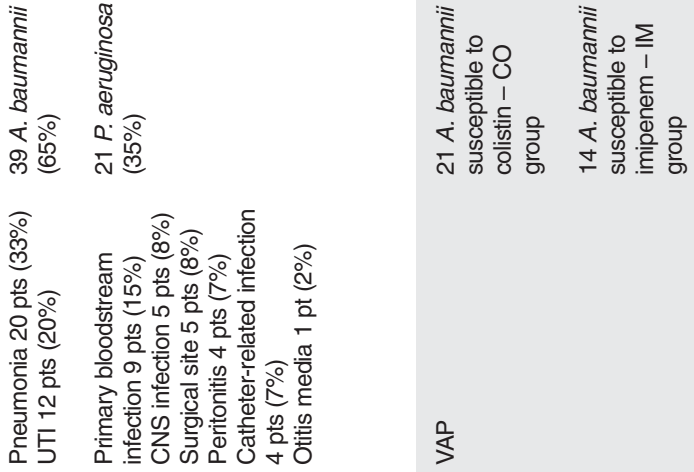

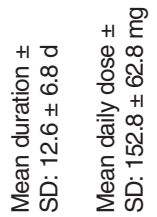

$\stackrel{0}{s}$

$\sum_{0}^{\infty}$

$\sum_{0}^{\infty}$

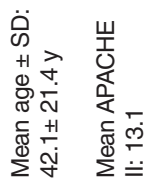

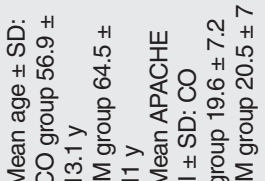

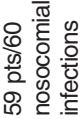

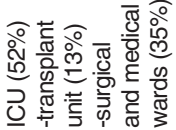

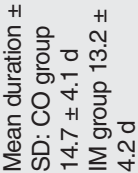

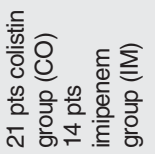

$\underline{\mathrm{J}}$

g

ङ 


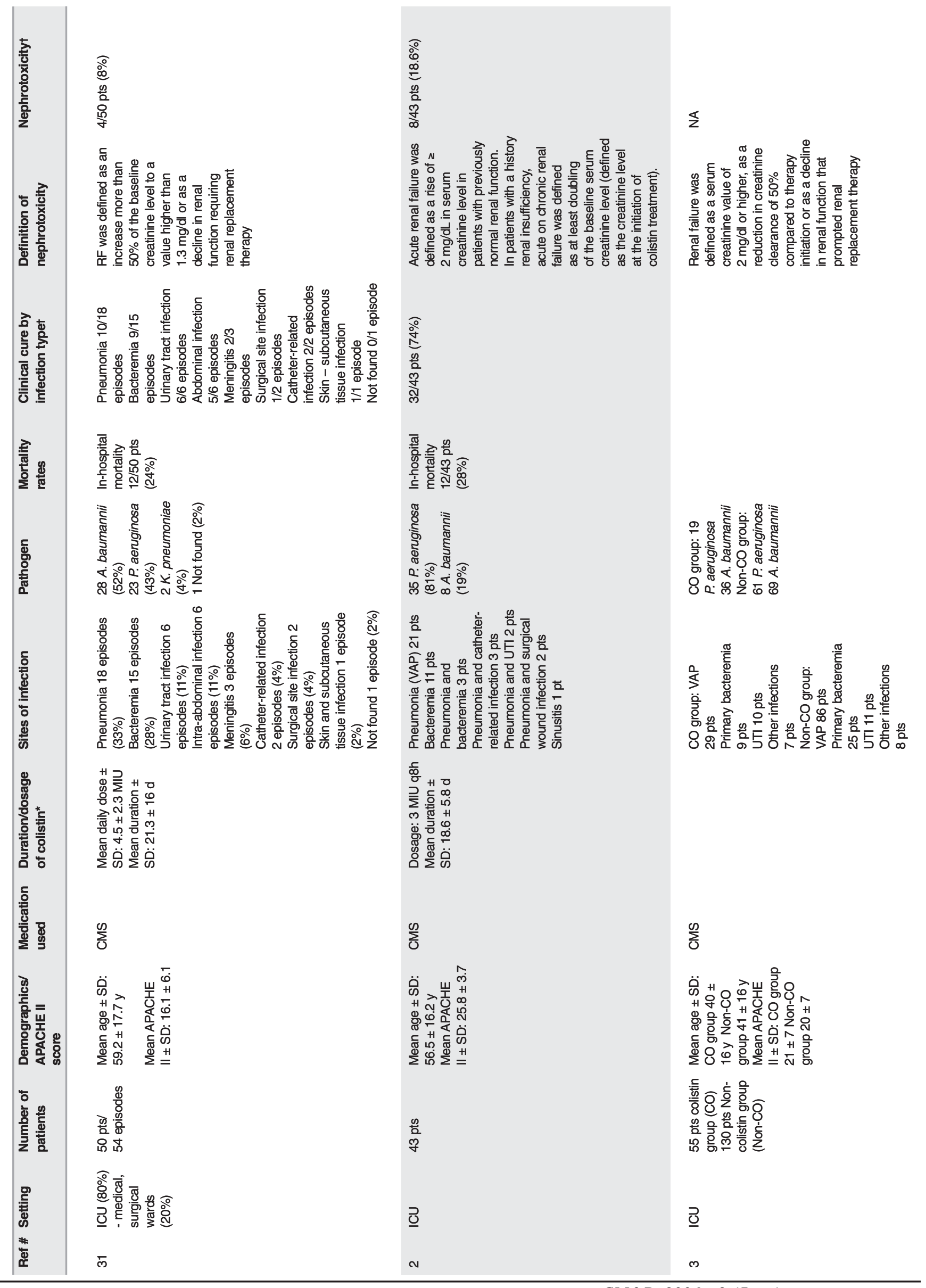

Polymyxins for treatment of infection 


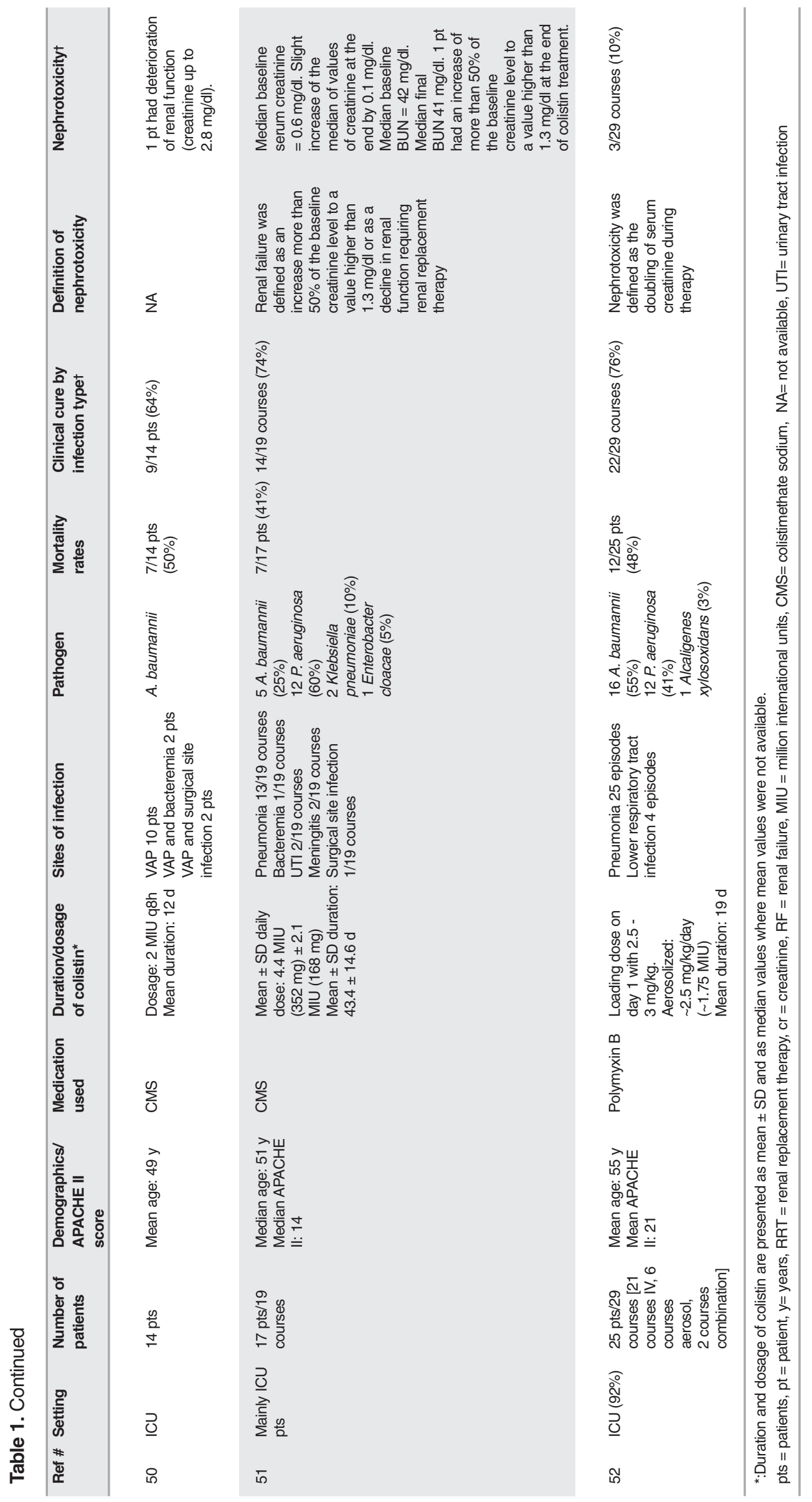


unit. Thus, definite statements regarding the effectiveness of intravenous polymyxins as monotherapy cannot be made. ${ }^{31-33} \mathrm{In}$ a comparative observational study of intravenous colistimethate sodium versus intravenous meropenem for the treatment of intensive care unit patients with Acinetobacter baumannii ventilator-associated pneumonia, the observed outcomes, including in-hospital mortality, ventilator-associated pneumonia-related mortality and clinical cure, were comparable. ${ }^{34}$

\section{Inhaled Polymyxins in Critically III Patients}

There is no extensive experience with the use of aerosolized polymyxins for the treatment of critically ill patients with respiratory tract infections caused by multidrug-resistant Gram-negative bacteria. On the contrary, their value in preventing and treating infections due to Pseudomonas aeruginosa in patients with cystic fibrosis has been thoroughly established. ${ }^{35-37}$ It is worth noting that the necessity to improve the outcome among patients with pneumonia due to multidrug-resistant bacteria has led to the use of alternative methods for administration of polymyxins. Most of the experience using aerosolized polymyxins is with colistin and is likely due to the fact that polymyxin B can lead more frequently than colistimethate sodium to release of histamine during nebulization and thus, bronchoconstriction. ${ }^{38,39}$

Table 2 (page 144) presents the limited evidence that exists in the recent literature with respect to the use of colistimethate sodium by nebulization in patients in the critical care setting. Aerosolized colistimethate sodium has been used as supplementary therapy to conventional intravenous antibiotic treatment for nosocomial pneumonia caused by multidrug-resistant Gram-negative microorganisms and was thought to be associated with improved outcome, suggesting that this approach merits further evaluation. ${ }^{40,41}$ Recently, 2 to 4 million IU per day of nebulized colistimethate sodium were administered to 21 patients with polymyxin-only susceptible Acinetobacter baumannii and Pseudomonas aeruginosa pneumonia leading to $85.7 \%$ successful clinical response. None of the patients in this study received intravenous colistimethate sodium concomitantly with aerosolized colistimethate sodium. They received other antibiotics that were, however, inactive against the isolated pathogen in vitro. ${ }^{42}$

\section{Toxicity}

The nephrotoxicity of polymyxins has been the major vexation limiting their clinical use. However, recent data, mainly from cases series, suggest that the use of polymyxins is relatively safe provided that recommended dosages are used, renal function is closely monitored and other potential nephrotoxic agents are avoided. The D-amino acid and fatty acid molecules of the structure of polymyxins have been associated with the development of nephrotoxicity, and the suggested mechanism resembles their mechanism of action. ${ }^{43-45}$
In an experimental model, colistin was bound to the apical membrane of the urothelium only when the membrane potential was cell interior negative and increased the transepithelial conductance of the urinary bladder epithelium. In addition, the magnitude of the increase in conductance was dependent on the concentration of colistin and on the voltage of the membrane. The presence of calcium and magnesium decreased the colistin-induced conductance. Moreover, long-term exposure of the membrane at high concentrations of colistin resulted in incomplete return of the transepithelial conductance to normal values after the removal of colistin, suggesting that prolonged exposure to high concentrations of colistin may be associated with toxic renal effects. ${ }^{46}$

Additionally, the use of polymyxins has been associated with the experience of several neurotoxic events, including dizziness, muscle weakness, facial and peripheral paresthesia, vertigo, confusion, ataxia and neuromuscular blockade, which can lead to respiratory failure or apnea. However, recent studies in critically ill patients are not consistent with the frequency of polymyxin-related neurotoxic events reported in the earlier literature. ${ }^{2,34}$ Treatment with aerosolized colistin may also be complicated with bronchoconstriction and chest tightness. ${ }^{36}$ However, treatment with aerosolized $\beta_{2}$-agonists before the initiation of aerosolized colistin could prevent the development of bronchoconstriction.

\section{Conclusion}

In conclusion, intravenous and aerosolized polymyxins should be considered for the treatment of critically ill patients with multidrug-resistant Gram-negative bacterial infections. Further research focusing on the appropriate dosage, clinical indications and safety profile of polymyxins is urgently needed. Meanwhile, strict use of polymyxins by clinicians worldwide is required to prevent the rapid development and dissemination of pandrug-resistant Gram-negative bacteria. ${ }^{1}$

\section{References}

1. Falagas ME, Bliziotis IA, Kasiakou SK, Samonis G, Athanassopoulou P, Michalopoulos A. Outcome of infections due to pandrug-resistant (PDR) Gram-negative bacteria. BMC Infect Dis 2005;5:24.

2. Michalopoulos AS, Tsiodras S, Rellos K, Mentzelopoulos S, Falagas ME. Colistin treatment in patients with ICU-acquired infections caused by multiresistant Gram-negative bacteria: the renaissance of an old antibiotic. Clin Microbiol Infect 2005; 11:115-121.

3. Reina R, Estenssoro E, Saenz G, Canales HS, Gonzalvo R, Vidal G, Martins G, Das Neves A, Santander O, Ramos C. Safety and efficacy of colistin in Acinetobacter and Pseudomonas infections: a prospective cohort study. Intensive Care Med 2005;31:1058-1065.

4. Fernandez-Viladrich P, Corbella X, Corral L, Tubau F, Mateu A. Successful treatment of ventriculitis due to carbapenem-resistant Acinetobacter baumannii with intraventricular colistin sulfomethate sodium. Clin Infect Dis 1999;28:916-917.

5. Kasiakou SK, Rafailidis PI, Liaropoulos K, Falagas ME. Cure of post-traumatic recurrent multiresistant Gram-negative rod meningitis with intraventricular colistin. J Infect 2005;50:348-352. 


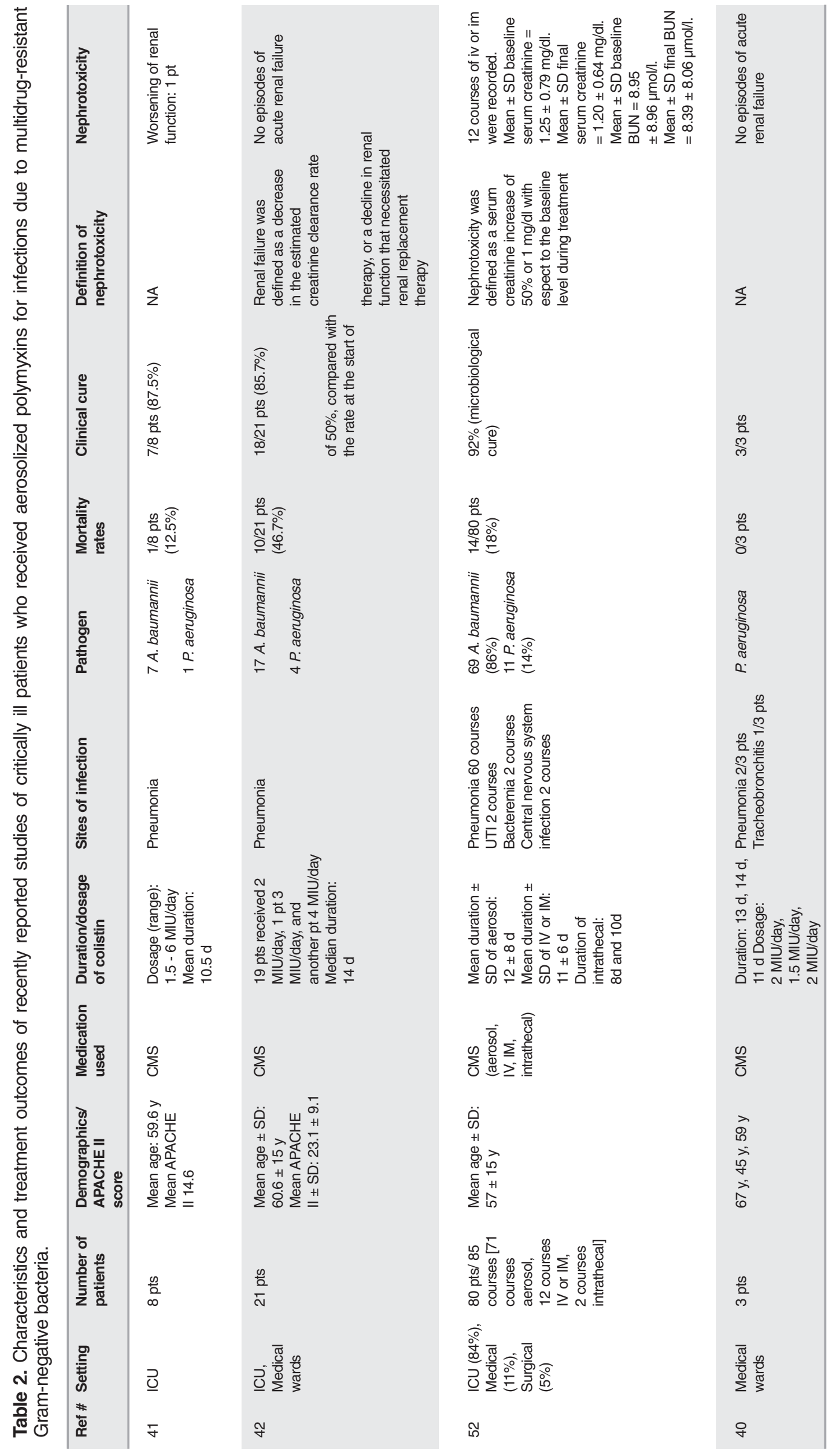


6. Segal-Maurer S, Mariano N, Qavi A, Urban C, Rahal JJ Jr. Successful treatment of ceftazidime-resistant Klebsiella pneumoniae ventriculitis with intravenous meropenem and intraventricular polymyxin B: case report and review. Clin Infect Dis 1999;28:1134-1138.

7. Falagas ME, Kasiakou SK. Colistin: the revival of polymyxins for the management of multidrug-resistant gram-negative bacterial infections. Clin Infect Dis 2005;40:1333-1341.

8. Fekety FR Jr, Norman PS, Cluff LE. The treatment of gram-negative bacillary infections with colistin. The toxicity and efficacy of large doses in forty-eight patients. Ann Intern Med 1962;57:214-229.

9. Koyama Y, Kurosasa A, Tsuchiya A, Takakuta K. A new antibiotic "colistin" produced by spore-forming soil bacteria. J Antibiot 1950;3:457-458.

10. Nord NM, Hoeprich PD. Polymyxin B and colistin. A critical comparison. N Engl J Med 1964;270:1030-1035.

11. Yow EM, Tan E, Shane L, Schonfeld S, Abu-Nassar H. Colistin (coly-mycin) in resistant bacterial infections. A clinical appraisal. Arch Intern Med 1961;108:664-670.

12. Flanagan AD. Adverse effects of sodium colistimethate. Ann Intern Med 1971;74:143-144.

13. Koch-Weser J, Sidel VW, Federman EB, Kanarek P, Finer DC, Eaton AE. Adverse effects of sodium colistimethate. Manifestations and specific reaction rates during 317 courses of therapy. Ann Intern Med 1970;72:857-868.

14. Tallgren LG, Liewendahl K, Kuhlbaeck B. The therapeutic success and nephrotoxicity of colistin in acute and chronic nephropathies with impaired renal function. Acta Med Scand 1965; 177:717-728.

15. Duncan DA. Colistin toxicity. Neuromuscular and renal manifestations. Two cases treated by hemodialysis. Minn Med 1973;56:31-35.

16. Elwood CM, Lucas GD, Muehrcke RC. Acute renal failure associated with sodium colistimethate treatment. Arch Intern Med 1966;118:326-334.

17. Lindesmith LA, Baines RD Jr, Bigelow DB, Petty TL. Reversible respiratory paralysis associated with polymyxin therapy. Ann Intern Med 1968;68:318-327.

18. Davis SD, Iannetta A, Wedgwood RJ. Activity of colistin against Pseudomonas aeruginosa: inhibition by calcium. J Infect Dis 1971;124:610-612.

19. Newton BA. The properties and mode of action of the polymyxins. Bacteriol Rev 1956;20:14-27.

20. Gough M, Hancock RE, Kelly NM. Antiendotoxin activity of cationic peptide antimicrobial agents. Infect Immun 1996;64:4922-4927.

21. Suzuki H, Nemoto H, Nakamoto H, Okada H, Sugahara S, Kanno Y, Moriwaki Continuous hemodiafiltration with polymyxin-B immobilized fiber is effective in patients with sepsis syndrome and acute renal failure. Ther Apher 2002;6:234-240.

22. Gales AC, Reis AO, Jones RN. Contemporary assessment of antimicrobial susceptibility testing methods for polymyxin B and colistin: review of available interpretative criteria and quality control guidelines. J Clin Microbiol 2001;39:183190.

23. Hogardt M, Schmoldt S, Gotzfried M, Adler K, Heesemann J. Pitfalls of polymyxin antimicrobial susceptibility testing of Pseudomonas aeruginosa isolated from cystic fibrosis patients. J Antimicrob Chemother 2004;54:1057-1061.

24. Coly-mycin M Parenteral (package insert). Bristol (TN): Monarch Pharmaceuticals, Inc. 2002.

25. Colomycin [package insert]. Bexley, UK: Forest Laboratories, UK Limited. 2002.

26. Polymyxin B for injection [package insert]. Bedford Laboratoties, Bedford, OH 44146. 1999.
27. Promixin 1 MIU powder for nebuliser solution [package insert]. West Sussex, UK: Profile Pharma Limited, UK. 2003.

28. Li J, Nation RL, Milne RW, Turnidge JD, Coulthard K. Evaluation of colistin as an agent against multi-resistant Gram-negative bacteria. Int J Antimicrob Agents 2005;25:11-25.

29. Tam VH, Schilling AN, Vo G, Kabbara S, Kwa AL, Wiederhold NP, Lewis RE. Pharmacodynamics of polymyxin B against Pseudomonas aeruginosa. Antimicrob Agents Chemother 2005;49:3624-3630.

30. Li J, Turnidge J, Milne R, Nation RL, Coulthard K. In vitro pharmacodynamic properties of colistin and colistin methanesulfonate against Pseudomonas aeruginosa isolates from patients with cystic fibrosis. Antimicrob Agents Chemother 2001;45:781-785.

31. Kasiakou SK, Michalopoulos A, Soteriades ES, Samonis G, Sermaides GJ, Falagas ME. Combination therapy with intravenous colistin for management of infections due to multidrug-resistant Gram-negative bacteria in patients without cystic fibrosis. Antimicrob Agents Chemother 2005;49:3136-3146.

32. Ouderkirk JP, Nord JA, Turett GS, Kislak JW. Polymyxin B nephrotoxicity and efficacy against nosocomial infections caused by multiresistant gram-negative bacteria. Antimicrob Agents Chemother 2003;47:2659-2662.

33. Sobieszczyk ME, Furuya EY, Hay CM, Pancholi P, Della-Latta P, Hammer SM, Kubin CJ. Combination therapy with polymyxin $\mathrm{B}$ for the treatment of multidrug-resistant Gram-negative respiratory tract infections. J Antimicrob Chemother 2004;54:566-569.

34. Garnacho-Montero J, Ortiz-Leyba C, Jimenez-Jimenez FJ, Barrero-Almodovar AE, Garcia-Garmendia JL, Bernabeu-WittelI M, Gallego-Lara SL, Madrazo-Osuna J. Treatment of multidrug-resistant Acinetobacter baumannii ventilator-associated pneumonia (VAP) with intravenous colistin: a comparison with imipenem-susceptible VAP. Clin Infect Dis 2003;36:1111-1118.

35. Conway SP, Pond MN, Watson A, Etherington C, Robey HL, Goldman MH. Intravenous colistin sulphomethate in acute respiratory exacerbations in adult patients with cystic fibrosis. Thorax 1997;52:987-993.

36. Cunningham S, Prasad A, Collyer L, Carr S, Lynn IB, Wallis C. Bronchoconstriction following nebulised colistin in cystic fibrosis. Arch Dis Child 2001;84:432-433.

37. Jensen T, Pedersen SS, Garne S, Heilmann C, Hoiby N, Koch C. Colistin inhalation therapy in cystic fibrosis patients with chronic Pseudomonas aeruginosa lung infection. J Antimicrob Chemother 1987;19:831-838.

38. Ishiura Y, Fujimura M, Myou S, Nobata K, Liu Q, Yamamori C, Amemiya T. In vivo airway eosinophil accumulation induced by polymyxin-B reduces bronchial responsiveness in guinea pigs. Clin Exp Allergy 2001;31:644-651.

39. Voitenko VG, Bayramashvili DI, Zebrev AI, Zinchenko AA. Relationship between structure and histamine releasing action of polymyxin B and its analogues. Agents Actions 1990;30:153-156.

40. Hamer DH. Treatment of nosocomial pneumonia and tracheobronchitis caused by multidrug-resistant Pseudomonas aeruginosa with aerosolized colistin. Am J Respir Crit Care Med 2000;162:328-330.

41. Michalopoulos A, Kasiakou SK, Mastora Z, Rellos K, Kapaskelis AM, Falagas ME. Aerosolized colistin for the treatment of nosocomial pneumonia due to multidrug-resistant Gram-negative bacteria in patients without cystic fibrosis. Crit Care 2005;9:R53-R59.

42. Kwa AL, Loh C, Low JG, Kurup A, Tam VH. Nebulized colistin in the treatment of pneumonia due to multidrug-resistant Acinetobacter baumannii and Pseudomonas aeruginosa. Clin Infect Dis 2005;41:754-757. 
43. Barnett M, Bushby SR, Wilkinson S. Sodium sulphomethyl derivatives of polymyxins. Br J Pharmacol Chemother 1964;23:552-574.

44. Berg JR, Spilker CM, Lewis SA. Effects of polymyxin B on mammalian urinary bladder. J Membr Biol 1996;154:119-130.

45. Berg JR, Spilker CM, Lewis SA. Modulation of polymyxin B effects on mammalian urinary bladder. Am J Physiol 1998;275:F204-F215.

46. Lewis JR, Lewis SA. Colistin interactions with the mammalian urothelium. Am J Physiol Cell Physiol 2004;286:C913-C922.

47. Linden PK, Kusne S, Coley K, Fontes P, Kramer DJ, Paterson D. Use of parenteral colistin for the treatment of serious infection due to antimicrobial-resistant Pseudomonas aeruginosa. Clin Infect Dis 2003;37:e154-e160.

48. Markou N, Apostolakos H, Koumoudiou C, Athanasiou M, Koutsoukou A, Alamanos I, Gregorakos L. Intravenous colistin in the treatment of sepsis from multiresistant Gram-negative bacilli in critically ill patients. Crit Care 2003;7:R78-R83.

49. Levin AS, Barone AA, Penco J, Santos MV, Marinho IS, Arruda EA, Manrique EI, Costa SF. Intravenous colistin as therapy for nosocomial infections caused by multidrug-resistant Pseudomonas aeruginosa and Acinetobacter baumannii. Clin Infect Dis 1999;28:1008-1011.

50. Petrosillo N, Chinello P, Proietti MF, Cecchini L, Masala M, Franchi C, Venditti M, Esposito S, Nicastri E. Combined colistin and rifampicin therapy for carbapenem-resistant Acinetobacter baumannii infections: clinical outcome and adverse events. Clin Microbiol Infect 2005;11:682-683.

51. Falagas ME, Rizos M, Bliziotis IA, Rellos K, Kasiakou SK, Michalopoulos A. Toxicity after prolonged (more than four weeks) administration of intravenous colistin. BMC Infect Dis 2005;5:1.

52. Berlana D, Llop JM, Fort E, Badia MB, Jodar R. Use of colistin in the treatment of multiple-drug-resistant gram-negative infections. Am J Health Syst Pharm 2005;62:39-47.

\section{Author Affiliations}

Matthew E. Falagas, MD; Alfa Institute of Biomedical Sciences, Athens, Greece; Department of Medicine, Henry

Dunant Hospital, Athens, Greece; and Department of Medicine, Tufts University School of Medicine, Boston, Massachusetts

Sofia K. Kasiakou, MD; Alfa Institute of Biomedical Sciences, Athens, Greece

Sotirios Tsiodras, MD; Department of Medicine, Attikon General University Hospital, University of Athens School of Medicine, Athens, Greece

Argyris Michalopoulos, MD; Intensive Care Unit, Henry Dunant Hospital, Athens, Greece 